\title{
Poverty and inequality - but of what - as social determinants of health in Africa?
}

\author{
Eshetu B. Worku ${ }^{1}$, Selamawit A.Woldesenbet ${ }^{2}$
}

1. Department of Health

2. Health Systems Research Unit, Medical Research Council

\begin{abstract}
Background: Many African economies have achieved substantial economic growth over the past recent years, yet several of the Millennium Development Goals (MDGs) including those concerned with health, remain considerably behind target. This paper examines whether progress towards these goals is being hampered by existing levels of poverty and income inequality. It also considers whether the inequality hypothesis of Wilkinson and Pickett ${ }^{1}$ applies to population health outcomes in African states.
\end{abstract}

Methods: Correlation analysis and scatter plots were used to assess graphically the link between variations in health outcomes, level of poverty and income inequality in different countries. Health status outcomes were measured by using four indicators: infant and under-five (child) mortality rates; maternal mortality ratios; and life expectancy at birth. In each of the 52 African nations, the proportion of the population living below the poverty line is used as an indicator of the level of poverty and Gini coefficient as a measure of income inequality. The study used a comprehensive review of secondary and relevant literature that are pertinent in the subject area. The data datasets obtained online from $\mathrm{UNICEF}^{2}$ and $\mathrm{UNDP}^{3}(2009)$ used to test the research questions. World Health Organization the three broad dimensions to consider when moving towards better population health outcome through Universal Health Coverage and the Social Determinants of Health framework reviewed to establish the poverty and income inequality link in African countries population health outcomes.

Results: The study shows that poverty is strongly associated with all health outcome differences in Africa (IMR, $c c=0.63$; U5MR, $c c=0.64 ;$ MMR, $c c=0.49$; life expectancy at birth, $c c=-0.67)$; income inequality with only one of the four indicators (IMR, cc $=0.14$; U5MR, cc $=0.07$; MMR, $c c=0.22$; life expectancy at birth, cc $=-0.49$ ), whereas income inequality is associated with one of the four indicators.

Conclusion: The study shows that tackling poverty should be the immediate concern in Africaas a means of promoting better health for all. There is a question mark over whether the findings of Wilkinson and Pickett ${ }^{1}$ on the relationship between income inequality and health apply to Africa. The reasons for this question mark are discussed. More research is needed to investigate whether the inequality results found in this study are replicated in other studies of African health.

Keywords: Health inequalities, poverty, income inequality, MDGs, social determinants of health, Africa

DOI: http://dx.doi.org/10.4314/ahs.v15i4.36

Cite as: Worku EB, Woldesenbet $S A$. Poverty and inequality - but of what - as social determinants of health in Africa? Afri Health Sci. 2015;15(4):1330-8. bttp:/ / dx.doi.org/10.4314/abs.v15i4.36

\section{Introduction}

According to United Nations ${ }^{4,5,6}$ reports assessing global efforts to achieve health and poverty-related Millennium Development Goals (MDGs) by 2015, many African countries are not on track to meet the goals. Each year, millions of mothers, new born babies and children continue to die in Africa from avoidable and treatable diseases. For instance, Africa's average infant mortality

\section{Corresponding author: \\ Eshetu B. Worku, Department of Health \\ Email: eworku@ncpg.gov.za}

rate (77 per 1,000 live births) is almost ten times that of most developed countries (8 per 1,000 live births). According to the Economic Commission for $\mathrm{Africa}^{7}$, child mortality figures are as high as 262 per 1,000 live births in the region. Over the period 1990 to 2005 the vast majority of African countries have only achieved negligible reductions in child mortality rates (1.8 percent). Maternal mortality rates in many African countries stand at more than 500 per 100,000 live births. Africa as a whole experiences one of the lowest life expectancies at birth (55 years) in the world. For African countries to reach their stated MDGs, current maternal and child mortality rate must be reduced to 228 per 100,000 and 61 per 1,000 live births respectively ${ }^{4}$. This raises the question , what actions can be taken at different levels to step torwards attaining the MDGs. 
Africa is still not well placed to meet its health-related Millennium Development Goals in 2015. Income differentials between rich and poor nations are widening ${ }^{8}$, . Disparities with regards to income and access to basic health and other social services are crucial factors that hinder the reduction of poverty and ill-health for the majority of Africans ${ }^{10}, 11,12,13$.

A substantial proportion of Africans live below the poverty line. A focus on poverty alone however might not be the best way to improve population health. Another factor is income inequality. Empirical evidence suggests that it is impossible to address health-related problems without simultaneously addressing economic problems ${ }^{14}$. The channel through which a healthy population is an engine for economic growth and conversely wealth undoubtedly leads to better health. How society organizes its scare resources for production and the distribution of both income and wealth has significant impact on health and well-being ${ }^{15}$. For instance, poor people who are economically or socially disadvantaged often suffer from an increasing burden of the social determinants and consequently worse health, on average, than their better-off-counterparts ${ }^{16}$. If the inequitable distribution of income across population groups remains unchecked or is allowed to worsen, then economic growth may not result in the health gains anticipated. The adverse impact of income inequality on health has been demonstrated ${ }^{17},{ }_{18}^{18},{ }^{1}$. More egalitarian societies have been identified with lower health inequality. We hypothesize that in the African context, policies aimed at improving overall health status need to tackle both poverty and income inequality if they are to be successful in achieving their intended goal.

Three hypotheses for the slow progress towards achieving the MDG targets in health to date could be offered. First, there is severe and deep-rooted poverty in the region. Secondly, large income inequality contribute both to the health gaps between the rich and the poor and exacerbates the lack of progress made in improving the overall health status of the population and economic growth in Africa. Thirdly, for African countries inequalities in something other than income may be a better explanation of variations in health.

This study explores the extent to which poverty and income inequality account for the variability in health status in the African context. The study examines this link by using cross-sectional data from UNICEF $^{2}$ (2009) and UNDP ${ }^{3}$.

\section{Methods}

Data for this study was obtained from UNDP $1^{[1]}$ and UNICEF $2^{[2]}$ datasets. We used country level data on infant, child (i.e. under-five) and maternal mortality ratios and life expectancy at birth as the health outcome. The predictor variables used to analyze variations in these health outcomes are the proportion of households whose income are below the international poverty line of US $\$ 1.25$ per day (expressed in purchasing power parity terms) in 2007 and income inequality as measured by the Gini coefficient. The Gini coefficient is commonly used as a measure of inequality in income or wealth. Its value ranges from 0 to 1 , where a lower coefficient indicates a more equal distribution of income.

Data on these variables were obtained for each of the 52 African countries. The association between health outcome variables and level of poverty and income inequality was analysed using the statistical package STATA. Scatter diagrams were used to express graphically the association between variability in health status and the level of poverty and income inequality. Correlation coefficients among pairs of continuous variables and P-values from Pearson's chi-square tests of associations were calculated. $\mathrm{P}$-values less than 0.05 were used as a measure of significant associations at the $5 \%$ level.

As all datasets used for analysis were publicly available secondary datasets, it was not necessary to seek formal approval from the Human Research Ethics Committee.

\section{Results}

There is a large variation in health status across African countries. For instance, infant mortality rates vary from 11 (Seychelles) to 158 (Sierra Leone) per 1,000 live births. Sierra Leone's figure is nearly twice the average for the African region as a whole ( 77 per 1,000 live births). Sierra Leone also has the highest under-five mortality rates (262 per 1,000 live births), while the lowest is in Seychelles (13 per 1,000 live births). Swaziland has the lowest maternal mortality rate (5 per 100,000 live births) while the highest is again in Sierra Leone (1,800 per 100,000 live births). The average maternal mortality rate for the African region stands at 520 per 100,000 live births. Life expectancy at birth varies from 42 years in Angola to 82 years in Swaziland. The average life expectancy for Africa is 55 years. In the region, income inequality as measured by the Gini coefficient ranges from 0.30 for Ethiopia to 0.74 for Namibia. The Gini coefficient is over 0.50 in one-third of all African countries. 
Figure 1 below shows the association between infant mortality rates and the proportion of the population living below the international poverty line of US $\$ 1.25$. It demonstrates that as the percentage of the population living under the poverty line increases, so does the rate of infant deaths. The high value of the correlation coefficient (cc=0.63) and the low P-value (0.0000) indicate that there is a statistically significant positive association between the two variables. Poverty accounts for $39 \%$ of the infant mortality rate in the region.

Figure 1: Scatter diagram of infant mortality and the percentage of population living below the international poverty line of US\$1.25 per day for African countries

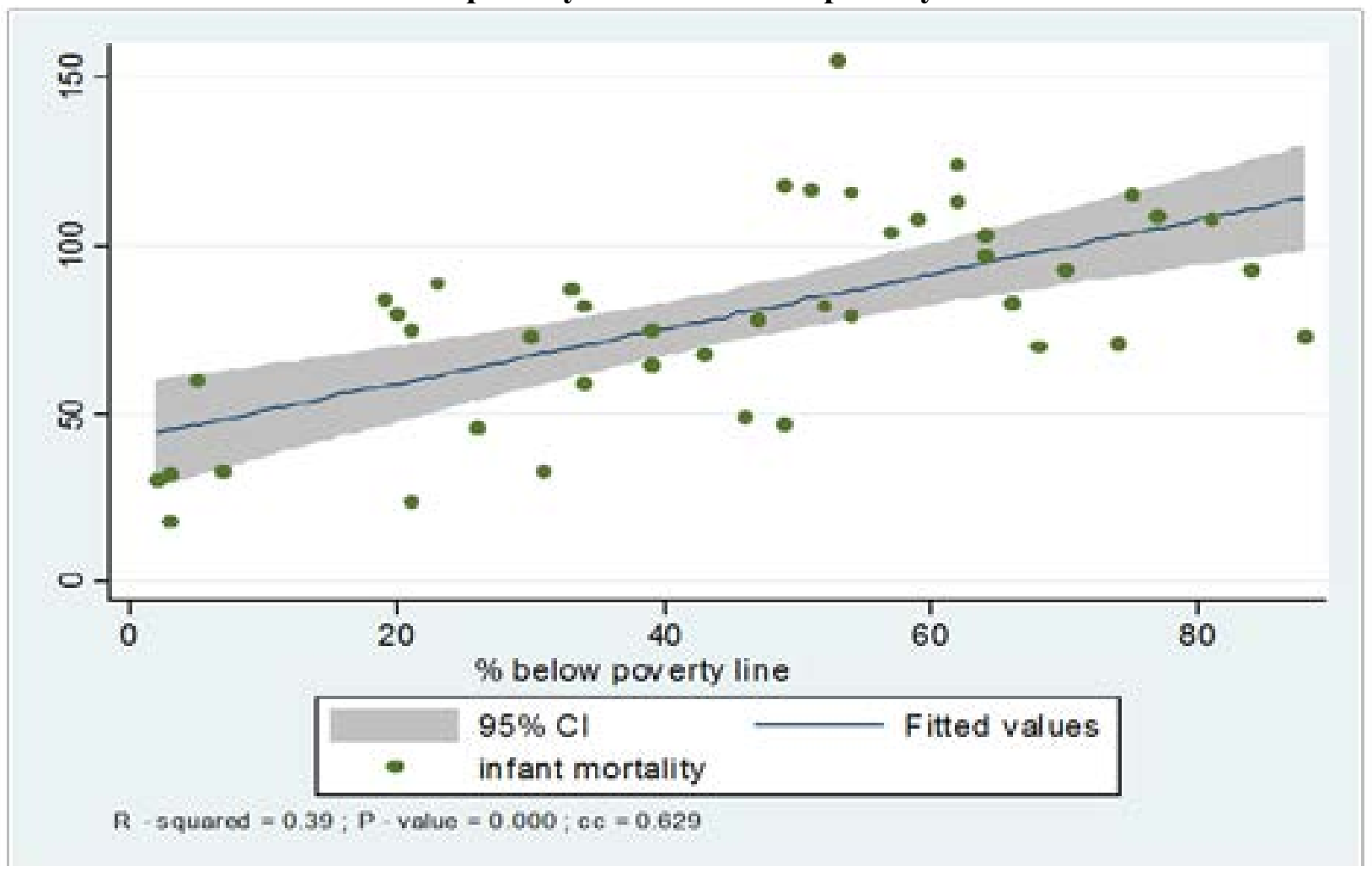

Figure 2 shows the relationship between the infant mortality rate and income inequality. There is no significant trend. Although there is a positive association between infant mortality and income inequality, the correlation coefficient $(\mathrm{cc}=0.143)$ and $\mathrm{R}$-squared $(\mathrm{R} 2=2.6 \%)$ are very small and reflect an insignificant causal association. The large $\mathrm{P}$-value $(\mathrm{P}=0.397)$ suggests that infant mortality is not well explained by income inequality in the African context.

\section{Figure 2: Scatter diagram of infant mortality rate and Gini coefficient} for African countries

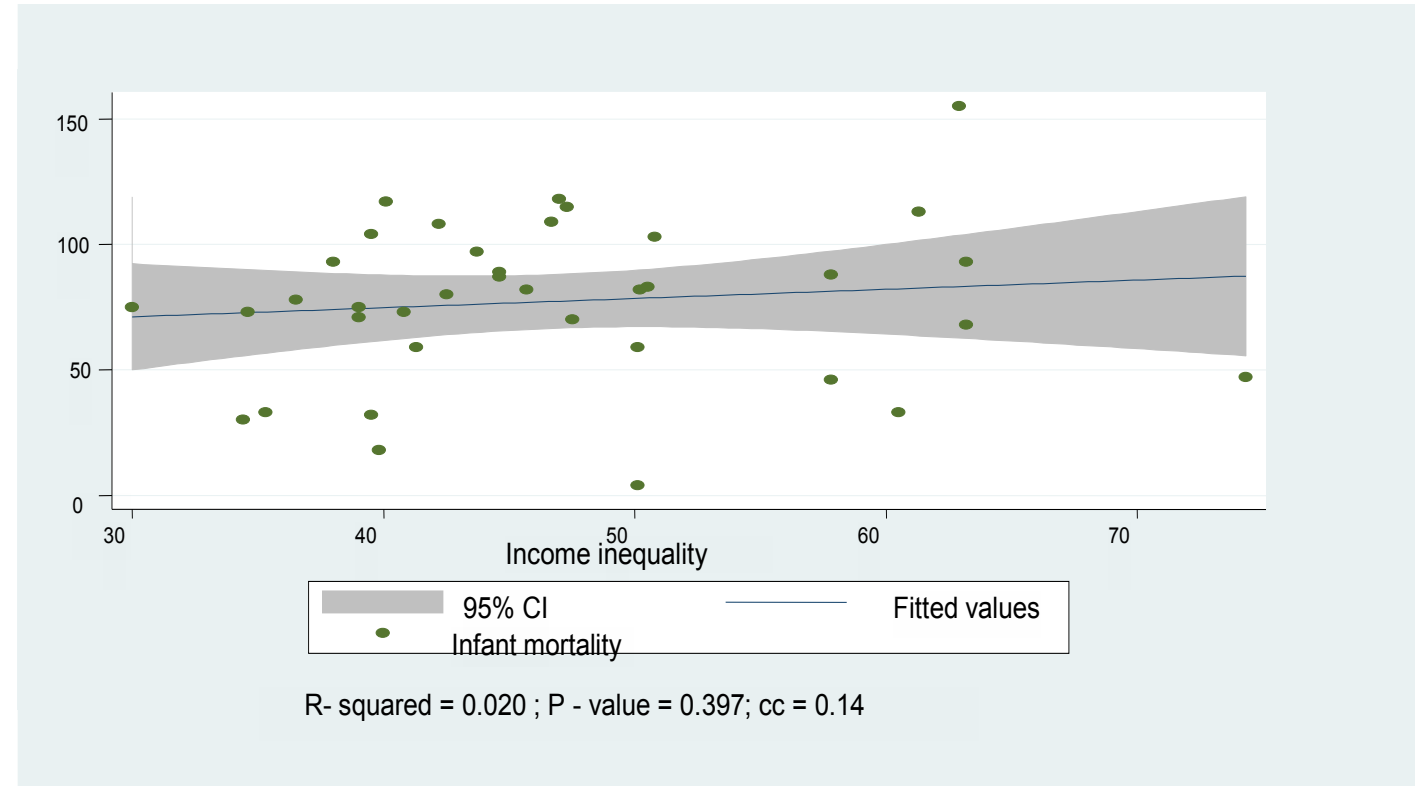


The association between child mortality and poverty is similar to the association between infant mortality and poverty, with a very low $\mathrm{P}$-value $(\mathrm{P}=0.000)$ and high correlation coefficient ( $\mathrm{cc}=0.6484)$. Similarly, as with infant mortality, there is a weak relationship between child mortality and income inequality, with a high P-value $(\mathrm{P}=0.650)$ and low correlation coefficient $(\mathrm{cc}=0.077)$.
Figure 3 presents the association between maternal mortality ratios and the proportion of the population living below the international poverty line. The diagram shows a positive association between the two, with a low $\mathrm{P}$-value $(\mathrm{P}=0.0001)$ and a high correlation coefficient $(\mathrm{cc}=0.4954)$.

Figure 3: Scatter diagram of maternal mortality ratio and the percentage of population below the international poverty line of US\$1.25 per day for African countries

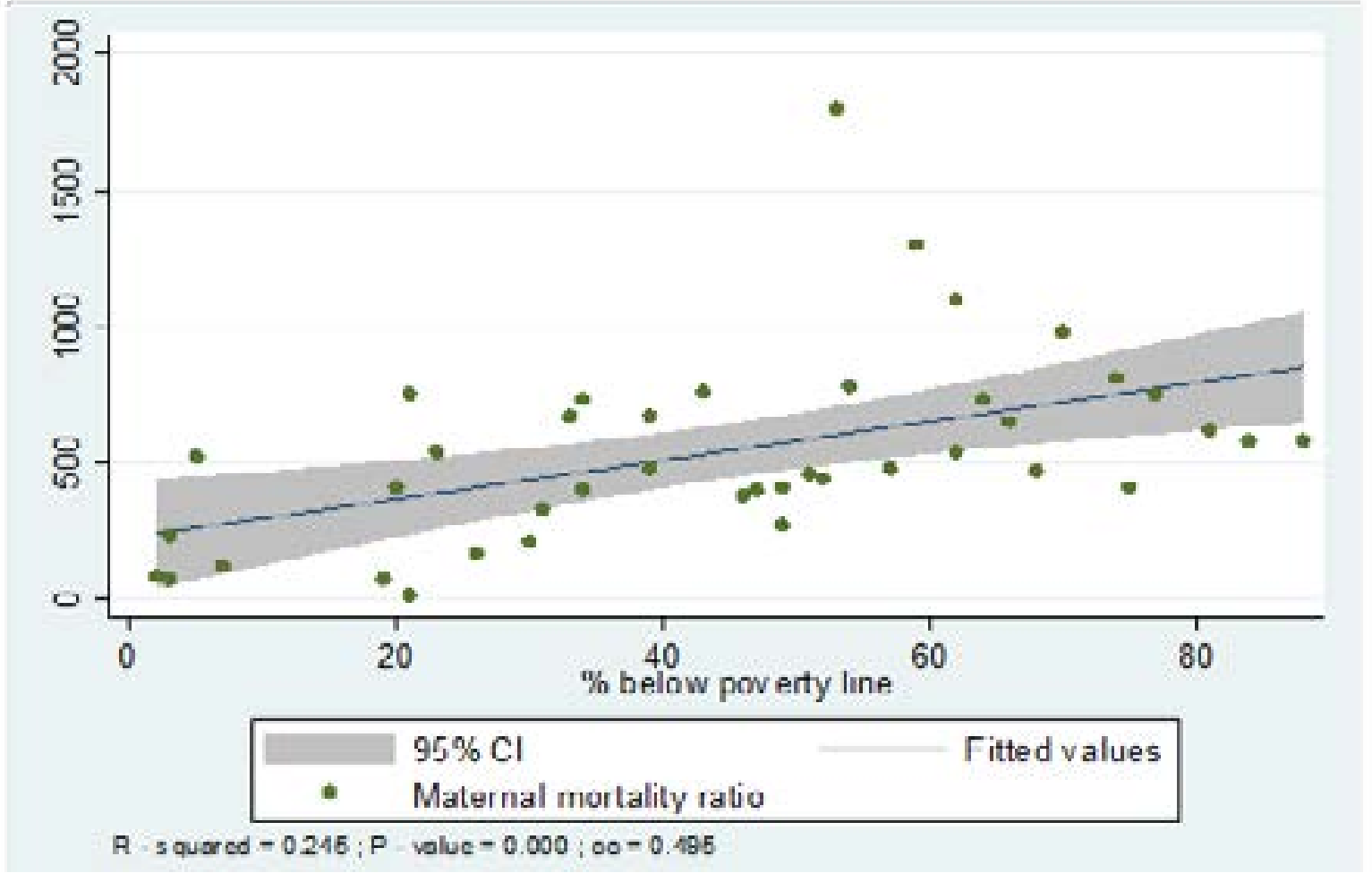

Figure 4 shows that there is an insignificant positive as- inequality, with a high $\mathrm{P}$-value $(\mathrm{P}=0.189)$ and a low corsociation between maternal mortality ratios and income relation coefficient $(\mathrm{cc}=0.224)$.

Figure 4: Scatter diagram of maternal mortality ratio and Gini coefficient for African countries

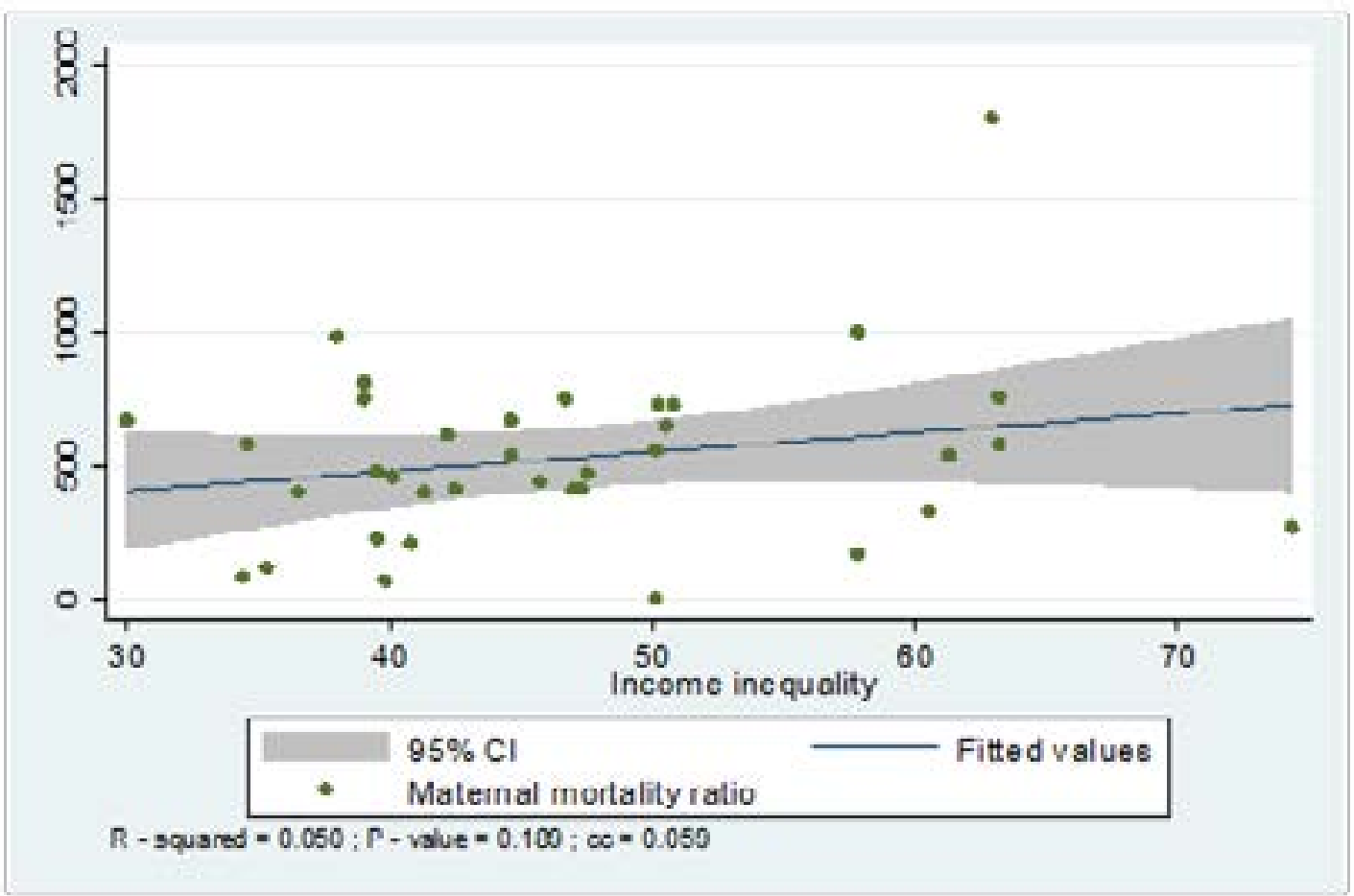


Figure 5 shows the relationship between life expectancy and the proportion of the population living below the international poverty line. There is a strong inverse relationship, with a low $\mathrm{P}$-value $(\mathrm{P}=0.000)$ and high negative correlation coefficient $(\mathrm{cc}=-0.702)$.

Figure 5: Scatter diagram of life expectancy at birth and the percentage of the population below the international poverty line of US\$1.25 per day for African countries

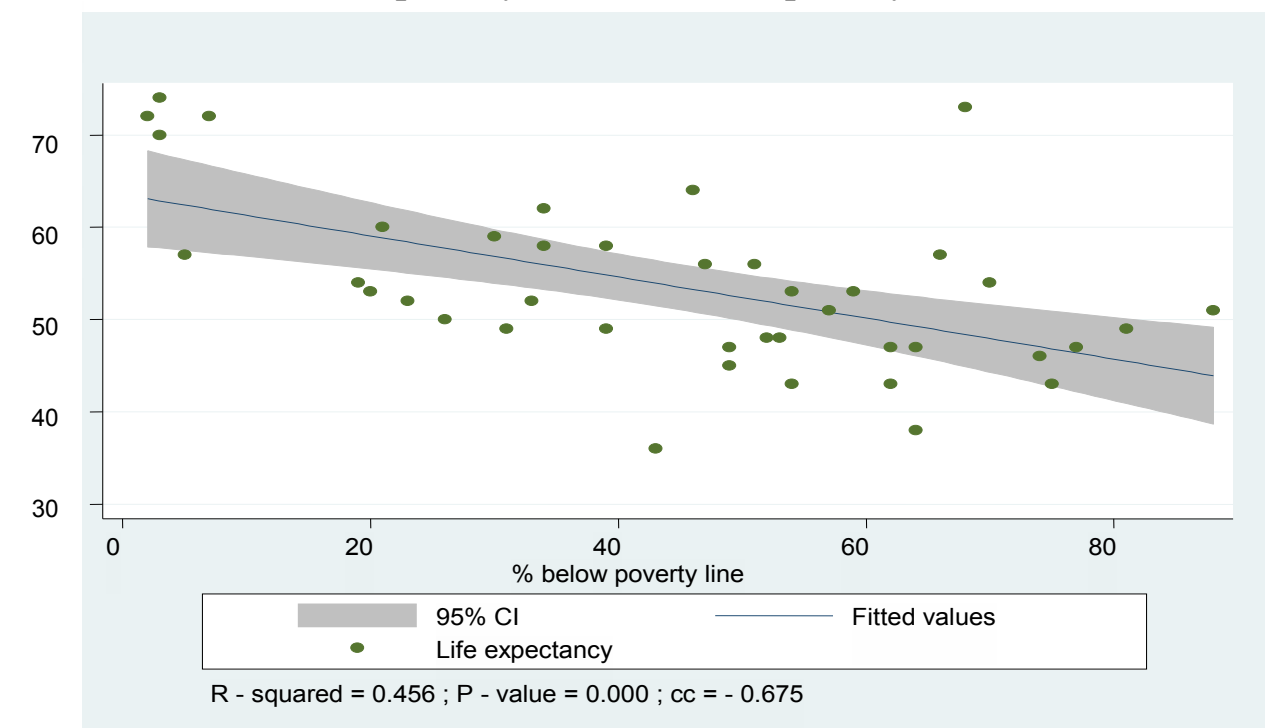

Figure 6 presents the scatter diagram of the association is again an inverse relationship, with a low P-value between life expectancy and income inequality. There $(\mathrm{P}=0.003)$ and a high but negative correlation coefficient (-0.495).

\section{Figure 6: Scatter diagram of life expectancy at birth by income inequality}

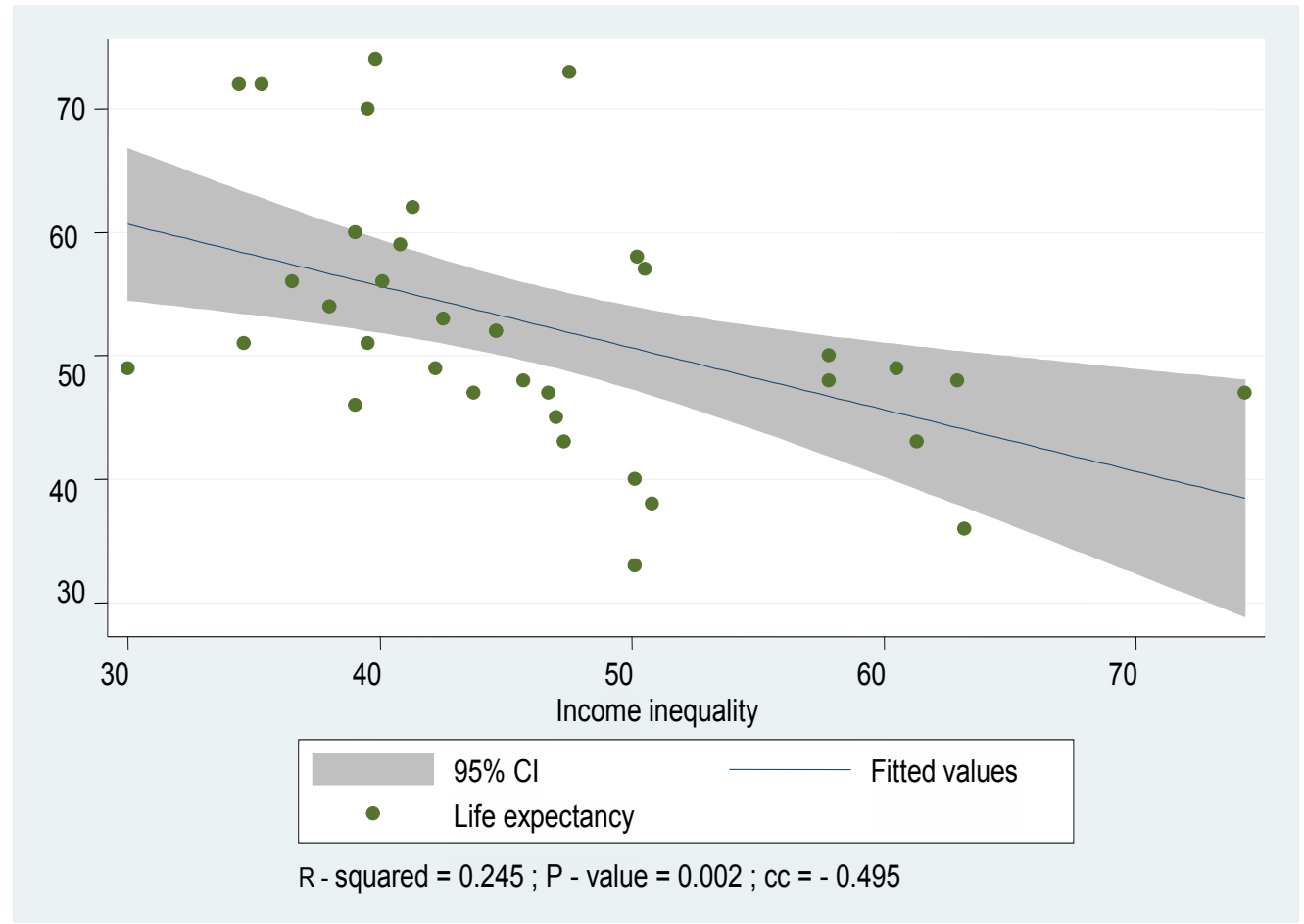




\section{Discussion}

There is a substantial body of evidence ${ }^{19}$ to support the idea that the health of a population is largely determined by the level of economic development of the country, as measured by gross domestic product (GDP) per capita. However, there is also evidence that it is not only the aggregate level of economic development, but also the distribution of economic resources within society, that impact on health outcomes ${ }^{20,21,22,23}$. Many researchers have reported a significant association between socio-economic factors and the ability of individuals to attain wellbeing in health ${ }^{24,25,21}$. Particular emphasis has been placed on the issue of income inequality recently in the work ${ }^{23,26}$. Societies with more unequal income distributions have poorer health outcomes than more egalitarian societies (Wilkinson and Pickett ${ }^{26}$, Marmot ${ }^{27}$, Subramanian and $\mathrm{Kawachi}^{28}$ ). However, it should be noted that, to date, this literature is dominated by studies conducted in developed countries.

Wilkinson and Pickett ${ }^{26}$ reviewed the international evidence on whether income inequality is a determinant of population health and explored the reasons why some societies are healthier than others. To that end, they reviewed a total of 168 peer-reviewed papers reporting on the association between income distribution and population health. Overall, they found that $78 \%$ of the studies showed at least some statistically significant evidence and that $70 \%$ were overwhelmingly supportive of the hypothesis that health status is worse in more unequal societies. However, $30 \%$ of studies found no statistically significant evidence to support this hypothesis. According to some researchers, the relationship between income inequality and population health remains a contested issue ${ }^{29,30}$.

One of the key findings of the study by Wilkinson and Pickett ${ }^{26}$ is that, when assessing the association between income inequality and health outcomes, the nature or level of geographical area within which income inequality is measured does matter. Where inequality was measured in small geographical areas, only a weak association with population health outcomes was generally reported. However, where inequality was measured in metropolitan areas, regions or whole countries, there was generally evidence confirming income inequality as a determinant of population health. The authors suggest that examining inequalities at the level of larger geographic areas reflects social class differences in a society.
With respect to the relationship between income inequality and poor health, with one exception, our study fails to establish any significant link. It is only with respect to life expectancy at birth that there is a significant and negative relationship with income inequality $(p=0.003 ; c c=-0.495)$. However, with respect to poverty, a strong relationship is established for all the health variables used infant mortality $(p=0.000 ; c c=0.63)$, under-five mortality $(\mathrm{p}=0.000$; $c \mathrm{c}=0.64)$, maternal mortality $(\mathrm{p}=0.000 ; \mathrm{cc}=0.495)$, and life expectancy at birth $(\mathrm{p}=0.000 ; \mathrm{cc}-0.67)$.

We propose four possible explanations for these findings. First, the finding suggesting that income levels, rather than income distribution, are most significant in affecting population heath in Africa may be due to poverty swamping other effects on health status. Considering the large proportion of the population in African countries living in conditions where they do not have the means to meet basic human needs poverty may dominate the influence of income inequalities. There are direct pathways between poverty and measures of health outcome considered here, such as through the relationship between poverty and undernourishment, lack of access to clean water, poor education, poor sanitation and lack of access to basic health care services ${ }^{15}$. Infant and child mortality increase as nutritional levels fall ${ }^{31}$. Studies in some countries suggest that women are more likely to bear more children (high fertility) and low birth weight babies where poverty levels are higher ${ }^{32,33}$.

A second possible explanation for the limited relationship between income inequality and health outcomes in the African context relates to the pathways through which income inequality affects health status. Wilkinson and Pickett ${ }^{26}$ argue that the link between health and income inequality is not about differential income per se but is in essence about class or social power structures. This leads us to speculate as to whether the role of income inequality as some sort of proxy forclass in a western society is less valid in Africa. There may be other political and social phenomena social power structures at work in African countries, which shape the distribution of ill-health and mortality among the population, and for which income inequality is not a good proxy. Another social power structure that is likely to be of relevance in Africa is that of gender power imbalances. Studies in many African countries indicate that gender inequalities can be substantial ${ }^{34,35}$ and can prevent women from attaining and maintaining better health. These issues of power structures in Africa and 
across different African countries with very different colonial pasts and tribal mixes need more research in the specific context of inequality and population health. Given very real limitations income inequality measures, the study suggest alternative indices for inequality; the gender empowerment measures, for example.

The third possible explanation is the issue of the lagged effect. One can expect income inequality in year $\mathrm{n}$ to influence health in $n+1$. This needs to study the lag time between income inequality and health status.

The final possible explanation is that a relationship between income inequalities and health outcomes may be obscured by measurement and data problems. Although it is generally accepted that the Gini coefficient is a good measure of income inequality, the emphasis on salaries from formal sector employment in measuring income may be problematic in many African countries. Informal sector activities and remittances are difficult to measure, and subsistence agricultural activities are often not taken into account. In addition, governments in many developing countries provide subsidized goods and services instead of cash payments to individuals or households. Thus, to base the Gini coefficient on cash income from formal sector activities alone may result in some bias in its measurement.

The health outcome measures available for the analysis may also have contributed to the limited association with income inequality. While there is very weak relationship between income inequality and infant and child mortality, there is a far stronger relationship between income inequality and life expectancy at birth. The most likely explanation for this is that life expectancy can be affected by events at various stages of life while this is not the case for the other health variables which are related to birth or the start of life. If the impact of income inequality does operate primarily or even in part through the reactions of people to being part of a hierarchical or class structure, these reactions will have a greater bearing on life expectancy than on factors such as infant or child mortality.

\section{Conclusions}

The majority of the African population lives in a state of abject poverty but also deepening income inequality. A recent World Bank ${ }^{36}$ report estimates that in sub-Saharan African countries, the share of income of the richest 20 per cent of the population is at least 18 times that of the poorest 20 per cent.
This paper attempted to show that focusing only on poverty and exclusion of income inequality would be too limiting in any debate about how best to improve population health in Africa. Contrary to our expectation however and contrary to the findings of previous studies, which have been restricted to Western countries with just one exception, our study fails to establish any significant link between income inequality and poor health in Africa. Infant, child and maternal mortality rates are associated with poverty, but not income inequality. This suggests that the relationship between income inequality and health should only exist for life expectancy and not other health measures. Because as these would not be influenced by social comparisons to the extent that life expectancy is. The inequality effect on life expectancy is important in Africa.

Many of the causes of ill-health and premature deaths in Africa are preventable, but they need adequate policy attention and resources. Efforts to reduce poverty and health disparities as stated in the Millennium Development Goals run the risk of failing to achieve their intended goals. Averting poor health requires improving living and working environments, proper nutrition, improved access to health care facilities, adequate incomes and a safe living environment. This paper shows that more research should be conducted in order to understand better how inequality, and if so, inequality of what, affects health in Africa. As Wilkinson and Pickett (2009 p. 28) argue, there is a need to 'regard the scale of material inequalities in a society as providing the skeleton round which class and cultural differences are formed'. The question of what proxy is best used in Africa in measuring inequalities needs to be addressed. It may not be income.

Tackling poverty is crucial for achieving better health. Addressing inequality in health is challenging unless economic inequality is simultaneously tackled by way of introducing suitable macro-economic and developmental policies. For instance, through redistribution of income could potentially improve that everyone has access to appropriate and equitable healthcare services. The poor cannot afford paying for their healthcare needs. This paper adds to the debate on inequality and health by exploring the complex relationship between poverty, income inequality and health in the specific context of African countries. Empirical evidence that supports a significant association between income inequality and health within this context is limited. The ef- 
fect of inequality in incomes and in other social factors on health in Africa needs further investigation.

\section{Limitation of the study}

This is a preliminary analysis report or hint on the link between variations in health outcomes, level of poverty and income inequality in different African countries cross-sectional data from UNICEF (2009) and UNDP (2009). Multivariate model, rather than bivariate correlation would be appropriate to know whether or not the poverty effect is truly independent of the inequality effect, and vice-versa, or perhaps they interact with each other. It is plausible that the effects of poverty are steeper in an environment of high inequality (when the very poor might compare themselves to the very rich). It is also possible that poor health causes more poverty and possibly inequality, too. In this study a multivariate model on poverty and inequality's has been greatly hampered by data issues, namely the limited number of indicators and often questionable comparability of the observations available for a multivariate cross-national analysis. The study calls for additional scholarship research on poverty and inequality consequences on health status in African countries.

\section{Acknowledgements}

This work is based upon research supported by the South African Research Chairs Initiative of the Department of Science and Technology and National Research Foundation. Any opinion, findings and conclusions or recommendations expressed in this material are those of the authors only. As such, the NRF and DST do not accept liability with regard thereto.

\section{References}

1. Wilkinson R, Pickett K. The spirit level. London: Allen Lane; 2009.

2. UNICEF. State of the World's Children 2009, Maternal and Newborn Health. New York: UNICEF. 2009. [Accessed on: 18/06/2012]. Available at http://www. unicef.org/sowc09/docs/SOWC09-FullReport-EN. pdf accessed on 14/03/12.

3. UNDP. Human Development Report. New York: United Nations Development Program. 2009. [Accessed on: 21/03/2012]. Available at http://hdr.undp. org/en/reports/global/hdr2009/

4. United Nations. Achieving the Millennium Development Goals in Africa. Recommendations of the MDG Africa Steering Group. New York: UN2008a. [Accessed on 22/03/2012]. Available at http://www.mdgafrica. org/pdf/MDG $\% 20$ Africa $\% 20$ Steering $\% 20$ Group $\% 20$ Recommendations $\% 20-\% 20$ English $\% 20-\% 20$ HighRes.pdf

5. United Nations. End poverty 2015. Millennium Development Goals Report. New York: UN2008b. [Accessed on 28/05/2012]. Available at http://www.un.org/millenniumgoals/reports.shtml

6. United Nations. The Millennium Development Goals Report 2009. New York: UN2009.

7. Economic Commission for Africa. Assessing Progress in Africa towards the Millennium Development Goals Report. 2008. [Accessed on: 14/04/2012]. Available at http://www.uneca.org/cfm/2008/docs/ AssessingProgressinAfricaMDGs.pdf [Accessed on 14/03/11]

8. Fosu A. Inequality and the impact of growth on poverty: Comparative evidence for Sub-Saharan Africa. Journal of Development Studies 2009; 45 (5), 726-745.

9. ILO. World of work report: Income inequalities in the age of financialglobalization. Geneva: International Institute for Labour Studies, International Labour Office 2008.

10. Hailu D, Soares S. What explains the decline in Brazil's inequality? Brasilia: International Policy Centre for Inclusive Growth, UNDP 2009.

11. Harsch E. Combating poverty in Africa. Lessen inequalities to reduce poverty and reach MDGs says UN. Africa Renewal 2006; 20 (2), 16 PubMed -18.

12. Economic Commission for Africa. MDGs in Africa a challenge for change: Tackling income inequality could help Africa quash extreme poverty 2005. [Accessed on 14/03/11]. Available at http://www.uneca. org/mdgs/Story31October06.asp

13. De Maio G. Ecological analysis of the health effects of income inequality in Argentina. Public Health 2008; 122(5), 487 PubMed -496.

14. Guillem L, Berta R, Luis C. Health and Economic Growth: Findings and policy Implications. The MIT Press 2005; ISBN: 0-262-12276-6

15. Eshetu W, Woldesenbet S. Are there particular social determinants of health for the world's poorest countries? African Health Sciences, Mar 2011; 11(1): $108 \mathrm{Pu}-$ bMed -115. PMCID: PMC3092326.

16. WHO. Health inequities in the South-East Asia Region: Selected country case studies: India: WHO 2009. 17. Epstein D, Jimenez-Rubio D, Smith P, Suhrcke M. Social determinants of health: An economic perspective. Health Economics 2009; 18, 495-502 PubMed . 
18. Subramanian V, Kawachi I, Smith D. Income inequality and the double burden of under- and overnutrition in India. Journal of Epidemiology \& Community Health 2007; 61(9), 802 PubMed -809.

19. WHO. Macroeconomics and health: Investing in health for economic development, Report of the Commission on Macroeconomics and Health. Geneva: WHO2001.

20. Walker D. Patterns of income distribution among world regions. Journal of Policy Modelling 2007; 29, 643655.

21. Moore S. Peripherality, Income Inequality, and Life Expectancy: Revisiting the Income Inequality Hypothesis." International Journal of Epidemiology 2006; 35(3):623. 22. Gerdtham G, Johannesson M. Absolute income, relative income, income inequality, and mortality. The Journal of Human Resources 2004; 39 (1), 228-247

23.Wilkinson R. Unhealthy Societies. London: Routledge1996.

24. Sen A. On Economic Inequality. New York: Norton1973.

25. Sen A. Poverty and Famines: An Essay on Entitlements and Deprivation. Oxford: Clarendon Press1981. 26. Wilkinson R, Pickett K. Income inequality and population health: A review and explanation of the evidence. Social Science and Medicine 2006; 62, 1768-1784.

27. Marmot M. Social determinants of health inequalities. The Lancet 2005; 365 (9464), 1099 PubMed -1104. 28. Subramanian S, Kawachi I. The association between state income inequality and worse health is not confounded by race. International Journal of Epidemiology 2003; 32, 1022-1028.

29. Zheng H. Rising US income inequality, gender and individual self-rated health, 1972-2004. Social Science and Medicine2009; 69 (9), 1333-134.
30. Deaton A. Health Inequality and Economic Development. Journal of Economic Literature 2003; 41 (1), 117 145.

31. Ferreira G, Schady N. Aggregate economic shocks, child schooling and child health. World Bank Research Observer2008; 24 (2), 147-181.

32. Williamson L, Parkes A, Wight D, Petticrew M, Hart G. Limits to modern contraceptive use among young women in developing countries: a systematic review of qualitative research. Reproductive Health2009; 6 (3). doi:10.1186/1742-4755-6-3

33. Karanja J. How income inequality affects health in a society 2009. [Accessed at: 09/09/2009]. Available at http://johnkaranja.com/2009/01/04/how-income-inequality-affects-health-in-society/

34. Moronkola O, Ojediran M, Amosu A. Reproductive health knowledge, beliefs and determinants of contraceptive use among women attending family planning clinics in Ibadan, Nigeria. African Health Sciences 2006; 6 (3), 155-159.

35. Pearce T. Women, the state and reproductive health issues in Nigeria. Journal of Culture and African Women Studies 2001; (1): 1. [Accessed on 14/03/11]. Available at http://www.africaknowledgeproject.org/index. $\mathrm{php} / \mathrm{jenda} /$ article/view/28

36. World Bank. World Development Indicators poverty data: A supplement to world development indicators 2008. [Accessed on 14/03/11]. Available at http:// siteresources.worldbank.org/DATASTATISTICS/Resources/WDI08supplement 1216.pdf

$1^{[1]}$ Human development reports : Available at http:// hdr.undp.org/en/reports/global/hdr2009/

$2^{[2]}$ State of the World's Children 2009, Maternal and newborn Health : Available at http://www.unicef.org/ sowc09/docs/SOWC09 